\title{
The Study of Leisure Experience, Perceived Value and Behavioral Intentions
}

\author{
Chih-Chiang Chung, Hui-Chen Lee*, Ching-Yi Lin \\ Graduate School of Leisure and Exercise Studies, National Yunlin University of Science and Technology, Taiwan
}

Copyright $\bigcirc 2016$ by authors, all rights reserved. Authors agree that this article remains permanently open access under the terms of the Creative Commons Attribution License 4.0 International License

\begin{abstract}
The purpose of the study was to discuss the relationship among leisure experience, perceived value and behavioral intentions for the tourists in Xitou Monster Village, Taiwan. 260 copies of questionnaire were distributed and 247 copies were effective. The data was analyzed by using descriptive statistics analysis, exploratory factor analysis, reliability analysis, validity analysis and linear structural equation modeling. The results were as follows: 1. The tourists background are mostly: female, 21 30 years old, living in the north, graduated from universities, monthly income under NT\$20,000, traveling with relatives, driving by self and introduced from friends; 2 . The result of path analysis indicated that leisure experience had a significant impact on perceived value; leisure experience had a positive effect on behavioral intentions; perceived value would positive affect on behavioral intentions. According to the result, suggestions and managerial implication also recommended.
\end{abstract}

Keywords Xitou Monster Village, Leisure Experience, Perceived Value, Behavioral Intentions

\section{Introduction}

Due to changes in the industrial structures, reduction in working hours as well as the government to promote two-day weekend, to make people conscious of the rise in leisure, participate in a variety of leisure activities prosperity in weekend, creating a coming era of the leisure, and also booming the leisure business and attracting management attentions.

While increasing in leisure awareness, and resulting to improving domestic tourist during weekends, furthermore, generating the advent of leisure time, leisure is the remaining time people stay away from working force to engage in activities other than working or regular life; and at the same time those leisure activities obtain the meaningful learning or attain some experiences or feelings (Kao, Wang, \& Chang, [1]), thus, how to relieving pressure by leisure traveling, enhance perspectives or escape from a formal life, to enrich the quality of life, has become people living styles.

In the issues of leisure industry management, marketing is a consumer-oriented business philosophy, focused on exploring and reaching the leisure needs of consumers, thereby promoting its leisure consumption conduct, to achieve business objectives in leisure industry, discussion on consumer behavior related issues, and those topics have become key issues for academic researches.

Xitou Nature Education Park comprise of ecological nature, is one of the important leisure attractions in Taiwan. Xitou Monster Village was formed with Japanese style of architecture and creative cultural district, is situated next to the entrance of Xitou Nature Forest Recreation Area, for example, chalet roof with hanging lantern, wearing traditional Japanese clothing kimono and shops provide a wide variety of unique goods and special souvenirs for tourist to choose, and tasty Japanese food, the whole village is full of Japanese-style of atmosphere, it becomes a major tourist attractions in Taiwan (Tourism Bureau, [2]). Therefore, there is an importance and necessity to explore the consumer behaviors in this tourist attraction.

\section{Literature Review}

Marketing is consumer-based management philosophy, with fierce competition in the market and rapid changes in the society, therefore, traditional marketing method would not be easy to attract consumers. Liu [3] believed in the advent of consumer experience era, consumption is no longer only means, instead purpose, because consumers ask for the depth and breadth of experience. Pine and Gilmore [4] pointed out that consumption is just a process for customers, memory of customer experience will not be disappear and permanently retained after consumption.

Bruner [5] believed that experience represent the consumer participating process, due to some excitement and stimulus, would change the perceptions of consumers, and as well as replace the activity itself. So the more accumulated experiences will become the basis of evaluation for consumer intentions to purchase tangible or intangible products. 
Schmitt [6] thought that experience is the personal matter in responding to certain stimuli, interactive results between consumers and products or situations to proposed the experiential marketing theory, that consumers not only want the products' features, but also the stimulate feelings. Experiential marketing will focus on the consumer experience, and believed that consumers are simultaneously driven by the emotional and rational, thus, experiential marketing emphasizes on building the entire consumption experiences. Shen, Tseng and Lin [7] mentioned that experience meant tourists would keep the deeply unforgettable memories in their minds, which is the core value of leisure traveling.

In addition, Schmitt [6] also mentioned two dimensions, strategic experiential models (SEMs) and experience providers (ExPros). SEMs are the basis of marketing strategy, the purpose is to create a various experience models, including five types: sense, feel, think, act and related; meanwhile, ExPros is the management framework offering communication panels between companies and consumers.

Chung [8] noted that due to the attention of consumption experience in experiential marketing, and focused on the process of forming the entire consumer experience to reach the marketing method for service industry to understand tourists' experience to assist tourists' leisure consumption behavior. Thus, one of purpose for the study was to explore the experiences of tourists.

There were studies applied in perceived value to measure the effectiveness of experience (Lai et al., [9]; Chen, Kuo, \& Chung, [10]). Zeithaml [11] noted that the perceived value was the total evaluation tool for customers' consumption and goods obtained. Mathwich, Malhotva and Rigdon [12] believed that perceived value of experience was reached for people from services, products directly obtained and used or remote enjoyment in distance. Chien [13] considered the value as the result of evaluation from consumers' feelings in affection, esthetic, and sense, after their spending on goods or services. Chang [14] indicated that the perceived value is measured by consumers inside feelings in the overall effectiveness ratio from the benefit of receiving and disbursement. Studies found that perceived value can influence consumer behavior (Petrick, [15]; Meng, Liang \& Yang, [16]); in the research of Fan, Liu and $\mathrm{Wu}$ [17] found that perceived value was an important indicator affecting behavior. So, if the leisure industry managers can handle the concept of perceived value for tourists to improve value experience, will enhance the efficiency of the leisure industry; therefore, the other purpose of the study was also to discover the perceived value feelings for tourists in the research.

Behavioral intention is the tendency of behaviors for tourists after consumption taken in specific activity (Engel, Blackwell, \& Miniard, [18]). Parasuraman, Berry and Zeithaml [19] pointed out that consumers' behavioral intentions can be regarded as business assessment indicators, when consumers after participating activities, according to their experience from consumption, resulting in awareness of the product, and thus lead to their behavioral intentions. Baker and Crompton [20] thought consumer behavior can be predicted from a behavioral intention, such as an appropriate measurement in behavioral intentions, the resulting data will be very close to the actual behavior. Kotler [21] also mentioned that the quality of products and services will stimulate favorable and unfavorable consumer behavioral intentions, leading to whether consumers and companies continue to maintain a relationship or take adverse action against. In today's consumer-oriented era, leisure industry managers who can effectively grasp the consumer behavioral intentions, that will build a good foundation for sustainable development, so in this study were not only to explore the experience and value of tourists, but also their behavioral intentions.

\section{Hypothesis}

In the relationship among leisure experience, perceived value and behavioral intentions, many studies have found that among leisure experience, perceived value and behavioral intention, between two related variables exist, but less at the same time explore the relationship among the three. In relationships between tourists' experiences and perceived values, Chen and Chen [22] in the study of tourists found that the experience will positively affect the perceived value; Chen, Kuo and Chung [10] also found that leisure experience has a positive impact on the perceived value in leisure participants. Based on the above analysis of related studies, it can be directed out of the first hypothesis of this study,

H1: leisure experiences of tourists have a positive impact on the perceived value.

In the relationship between tourists' leisure experiences and behavioral intentions, Chung et al. [23] in the study of tourists found that tourists' leisure experience will affect behavioral intention; the research from Prayag, Hosany and Odeh [24] also pointed out that tourists' leisure experiences will positively affect behavioral intentions. According to the above analysis of related studies, it can be leaded to the second hypothesis of this study,

H2: the tourists' leisure experience has a positive effect on behavioral intentions.

On the relationship between tourists' perceived value and behavioral intention, Hsu and Chung [25] in the study of hiking trails tourists found that perceived value will positively affect the behavioral intentions. Yi, Day and Cai [26] explored that the perceived value and behavioral intention in tourists study, also found that perceived value can influence the tourist behavioral intentions. According to the above studies, it can guide to a third hypothesis of this study,

H3: tourists' perceived value will have a positive impact on behavioral intentions.

Based upon the analysis, leisure experience, perceived value and behavioral intention, had correlation to each other, so the study also predicted that affective relationship among the presence of the three variables, 
H4: leisure experience will influence behavior intention through perceived value.

\section{Research Methodology}

\subsection{Research Sample}

The subjects of the study were tourists of Xitou Monster Village, the official questionnaire distributed in the day of April $4^{\text {th }}$ to $6^{\text {th }}, 2014$, at the business center of Xitou Monster Village. To make sure the subjects must have actual experience in monster village, every respondent would be investigated if they have been in monster village, and then could reply to the survey without the misunderstanding and ensure they have the concepts regarding to monster village, to fulfill the purpose of measurement effectiveness, and with convenience method to select subjects. A total of 260 questionnaires distributed, and 247 valid with recovery rate of $95 \%$.

\subsection{Instrument}

In this study, the use of leisure experience, perceived value and behavioral intention to explore the relationship among the three variables, the process of inventory and contents as follows:

\subsubsection{Leisure Experience Scale}

Leisure experience scale was consulting from Schmitt [6] referred to the experience of five modules; and Shen, Tseng and Lin [7] tourist leisure experience, and then based on the characteristics of the study, as amended. A total of 25 questions formed and with Likert five-point scale, 5 meant very satisfied, and 1 was very unsatisfied, thus higher score indicated tourists agreed more about this experience. Item analysis was used with two methods, critical ratio and correlations (the relationship among the average of each item and the sum of all items). The analysis found, the critical ratio range between $6.75 \sim 11.30(\mathrm{p}<.05)$, the correlation coefficient was $0.57 \sim 0.75(\mathrm{p}<.05)$, reached acceptable standards. Followed by factor analysis, principal component analysis to extract factors with oblique rotation, excluding the subject factor loadings less than 0.4 (Q9, Q13, Q14) and cross-subject factors (Q19), and attained three factors, named travel experience, act experience and social experience (see Table 1). On the scale reliability and validity of the test, the Cronbach's $\alpha$ value reached in high acceptable standard ( 0.82 to 0.91$)$, while the scale of the total variance explained was $58.95 \%$ (see Table 1), thus the scale had acceptable reliability and construct validity.

Table 1. Factor analysis and reliability of leisure experience in Xitou Monster Village

\begin{tabular}{|c|c|c|c|c|c|}
\hline Item Content & $\begin{array}{c}\text { Travel } \\
\text { exp. }\end{array}$ & $\begin{array}{l}\text { Act } \\
\text { exp. }\end{array}$ & $\begin{array}{l}\text { social } \\
\text { exp. }\end{array}$ & average & S. D. \\
\hline Unique architecture and furnishings & 0.84 & & & 4.32 & 0.60 \\
\hline Character design is very intentions & 0.76 & & & 4.28 & 0.67 \\
\hline Environment has a Japanese-style enjoyment & 0.77 & & & 4.31 & 0.68 \\
\hline Beautiful natural landscape near by & 0.71 & & & 4.41 & 0.69 \\
\hline The events gives me great visual enjoyment & 0.72 & & & 4.05 & 0.83 \\
\hline The casual atmosphere to meet my leisure needs & 0.71 & & & 4.02 & 0.77 \\
\hline I think the monster village has a unique style & 0.46 & & & 4.17 & 0.74 \\
\hline Full of festive atmosphere & 0.63 & & & 4.36 & 0.67 \\
\hline Travel in monster village makes me feel good & 0.59 & & & 4.19 & 0.75 \\
\hline Travel in monster village to meet my curiosity & 0.43 & & & 4.07 & 0.76 \\
\hline Travel in monster village would enrich my life & 0.45 & & & 4.06 & 0.68 \\
\hline Showcase in monster village makes me wanted to take pictures & 0.42 & & & 4.43 & 0.69 \\
\hline After visiting the monster village, makes me wanted to know more about their brand story & & 0.76 & & 3.74 & 0.82 \\
\hline I will want to collect monster village activity information & & 0.42 & & 3.72 & 0.83 \\
\hline I'll peruse monster village brand story & & 0.73 & & 3.70 & 0.83 \\
\hline Travel in monster village made me wanted to go to leisure activities & & & 0.57 & 3.98 & 0.76 \\
\hline Travel in monster village can enhance the relationship between my family and friends & & & 0.65 & 4.15 & 0.75 \\
\hline Travel in monster village can allow to meet like-minded friends & & & 0.84 & 3.68 & 0.89 \\
\hline Been to monster village can enhance chatting with others & & & 0.71 & 3.97 & 0.82 \\
\hline I'll start thinking about the relationship between man and other creatures & & & 0.80 & 3.49 & 0.90 \\
\hline I think the monster village participate in the activities, so that I and others associate & & & 0.82 & 3.64 & 0.85 \\
\hline Eigenvalues & 9.19 & 1.21 & 1.98 & & \\
\hline$\%$ variance & 43.76 & 9.45 & 5.74 & & \\
\hline$\%$ accumulation & 43.76 & 53.21 & 58.95 & & \\
\hline Factor average & 4.22 & 3.72 & 3.82 & & \\
\hline Average rank & 1 & 3 & 2 & & \\
\hline Cronbach's $\alpha$ & 0.91 & 0.82 & 0.88 & & \\
\hline Total scale Cronbach's $\alpha$ & & 0.87 & & & \\
\hline
\end{tabular}


Table 2. Item analysis and reliability of perceived value in Xitou Monster Village

\begin{tabular}{|c|c|c|c|c|c|}
\hline Perceived value & CR & Correlation & Average & Standard Deviation & Rank \\
\hline Money spent in monster village, I think it is worth it & $13.20^{*}$ & $0.80^{*}$ & 3.62 & 0.77 & 4 \\
\hline Time spent in monster village, I feel that is worth it & $15.65^{*}$ & $0.86^{*}$ & 3.89 & 0.75 & 2 \\
\hline Physical energy and mental spent in monster village, I feel that is worth it & $13.98^{*}$ & $0.87^{*}$ & 4.04 & 0.68 & 1 \\
\hline Travel in monster village can actually meet my needs & $14.20^{*}$ & $0.81^{*}$ & 3.79 & 0.77 & 3 \\
\hline Cronbach's $\alpha$ & \multicolumn{5}{|c|}{0.87} \\
\hline
\end{tabular}

${ }^{*} \mathrm{p}<.05$

Table 3. Item analysis and reliability of behavioral intention in Xitou Monster Village

\begin{tabular}{|c|c|c|c|c|c|}
\hline Behavioral intention & CR & Correlation & Average & Standard Deviation & Rank \\
\hline If there is opportunity, I will come to the village again in the future & $12.26^{*}$ & $0.85^{*}$ & 3.99 & 0.74 & 3 \\
\hline I'll buy the relevant brand product or local specialty in monster village & $12.65^{*}$ & $0.77^{*}$ & 3.79 & 0.77 & 4 \\
\hline I will share information of monster village to other people & $12.80^{*}$ & $0.82^{*}$ & 4.17 & 0.66 & 1 \\
\hline $\begin{array}{c}\text { I would recommend friends and family to participate in activities } \\
\text { organized by the monster village }\end{array}$ & $14.85^{*}$ & $084^{*}$ & 4.02 & 0.75 & 2 \\
\hline \multicolumn{4}{|c|}{0.84} \\
\hline
\end{tabular}

${ }^{*} \mathrm{p}<.05$

\subsubsection{Perceived Value Scale}

Perceived value scale were formed according to Chen, Kuo, and Chung [10], in which contained four questions with Likert five-point scale, 5 meant strongly agree and 1 represented strongly disagree, thus, higher the score meant that higher agreement of the perceive value, please see Table 2. Item analysis of critical ratio of each item between $13.20 \sim$ $15.65(\mathrm{p}<.05)$, and correlation coefficient was $0.80 \sim 0.87$ $(\mathrm{p}<.05)$, reached acceptable standards. On the scale of reliability and validity, the Cronbach's $\alpha$ was 0.87 , that meant a high standard of acceptance; and the use of this four questions were from the review literatures to support the content validity, thus, the perceived value did have acceptable reliability and validity.

\subsubsection{Behavioral Intention Scale}

The behavioral intention scale was constructed by using Yeh, Hsu and Chung [27] in inventory of leisure intention with four questions and Likert five-point scale, 5 to 1 from strongly agree to strongly disagree, higher the score which represent that higher agreement of the behavioral intention, please see Table 3 . Critical ratio of item analysis between $12.26 \sim 14.85(\mathrm{p}<.05)$, and the correlation coefficient was $0.77 \sim 0.85(\mathrm{p}<.05)$, reached acceptable standards. On the scale reliability and validity of the test, the four questions of the internal consistency coefficient (Cronbach's a) was 0.84, showing the reliability of an acceptable standard; and the use of four questions were applied from literatures and related researches support with content validity and acceptable reliability and validity.

\section{Research Findings}

\subsection{Overview of Leisure Experience, Perceived Value and Behavioral Intentions}

Leisure experience, perceived value and behavioral intentions as shown in Table 1 to 3, "travel experience" factor had the highest score in leisure experience; "overall satisfaction" placed first in perceived value; "will share to others" ranked the highest score in behavioral intention. Overall, leisure experience, perceived value and behavioral intention are toward positively satisfaction or agreement.

\subsection{Structural Model of Leisure Experience, Perceived Value and Behavioral Intention}

The structural equation model was used, according to Huang [28], situational variables assigned if the absolute value is greater than 3, it was viewed as extreme skewness, kurtosis absolute value greater than 10 would be a problem, after statistics showed that all variables in this study of absolute value of skewness was 0.24 to 1.41 ; peak of the absolute value from 0.36 to 2.21 were within the acceptable range, thus, Maximum Likelihood (ML) was used to estimate the model.

Statistical results from using AMOS17 as shown in Table 4 , normalized parameter value between 0.29 to 0.86 , and most of the parameters was not too close to one (to 0.95 as the threshold). Standard error ranged from 0.07 to 0.17 , indicating that the error was not large, and there was no negative variation errors exist, and $t$ values all reach significant levels. As the results show that the model was not seriously irregularity in estimation, therefore it could be further verified in the model of fit.

On the mode of goodness of fit test, chi-square degrees of freedom ( $\left.x^{2} / d f\right)$, the Goodness Fit Index (GFI), the Root Mean Square Error of Approximation (RMSEA), Standardized Root Mean Residual (SRMR), Normed Fit Index (NFI), Comparative Fit Index (CFI), Parsimonious Goodness Fit Index (PNFI) for the overall evaluation. Each value of assessment of model and model fit was shown in Table 5 within a good degree of adaptation and acceptable model. 
The result of the study for leisure experience, perceived value and behavioral intention, all the parameters reached the significant level (see Figure 1); therefore, the four hypotheses were true. Leisure experience was measured by the three variables, namely travel experience, act experience and social experience, of which the highest path coefficient was travel experience; perceived value was measured by the four variables, namely money, time, mental and satisfaction, in which the value of highest path coefficients was mental; behavioral intentions was measured by the four variables, namely revisit, purchase, share information and recommendation to others, in which revisit was ranked the highest in coefficient. In the relationship of all latent variables, leisure experience will positively affect perceived value with path coefficient of 0.83 ; leisure experience will positively influence behavioral intention with 0.63 path coefficient; perceived value will affect behavioral intention positively of 0.29 path coefficient.

Table 4. Parameter estimation analysis

\begin{tabular}{|c|c|c|c|c|c|}
\hline \multicolumn{2}{|c|}{ Items } & Estimate & S. E. & $\mathrm{t}$ value & Standard Regression Weights \\
\hline \multicolumn{2}{|c|}{ Leisure experience $\rightarrow$ Perceived value } & 1.12 & 0.10 & $10.86^{*}$ & 0.83 \\
\hline \multicolumn{2}{|c|}{ Leisure experience $\rightarrow$ Behavioral intention } & 0.86 & 0.17 & $5.18^{*}$ & 0.63 \\
\hline \multicolumn{2}{|c|}{ Perceived value $\rightarrow$ Behavioral intention } & 0.29 & 0.12 & $2.46^{*}$ & 0.29 \\
\hline & Travel experience & 1.00 & --- & --- & 0.86 \\
\hline \multirow[t]{3}{*}{ Leisure experience } & Act experience & 1.17 & 0.09 & $12.36^{*}$ & 0.72 \\
\hline & Social experience & 1.08 & 0.08 & $12.28 *$ & 0.72 \\
\hline & Money value & 0.93 & 0.08 & $11.05^{*}$ & 0.71 \\
\hline \multirow[t]{4}{*}{ Perceived value } & Time value & 1.05 & 0.08 & $13.25^{*}$ & 0.83 \\
\hline & Mental value & 0.99 & 0.07 & $13.84 *$ & 0.86 \\
\hline & Satisfaction needs & 1.00 & --- & --- & 0.77 \\
\hline & Revisit & 1.00 & --- & --- & 0.82 \\
\hline \multirow[t]{3}{*}{ Behavioral intention } & Purchase products & 0.84 & 0.08 & $10.64 *$ & 0.65 \\
\hline & Share information & 0.85 & 0.06 & $13.10^{*}$ & 0.78 \\
\hline & Recommendation to others & 0.97 & 0.07 & $13.39 *$ & 0.77 \\
\hline
\end{tabular}

$* \mathrm{p}<.05$

Table 5. Overall Goodness of Fit Model

\begin{tabular}{|c|c|c|c|c|c|c|c|}
\hline & $x^{2} / d f$ & GFI & RMSEA & RMR & NFI & CFI & PNFI \\
\hline Measurement model & 2.54 & 0.93 & 0.079 & 0.02 & 0.94 & 0.96 & 0.70 \\
\hline Acceptable value & $\leqq 5$ & $\geqq 0.9$ & $\leqq 0.08$ & $\leqq 0.05$ & $\geqq 0.9$ & $\geqq 0.9$ & $\geqq 0.5$ \\
\hline
\end{tabular}

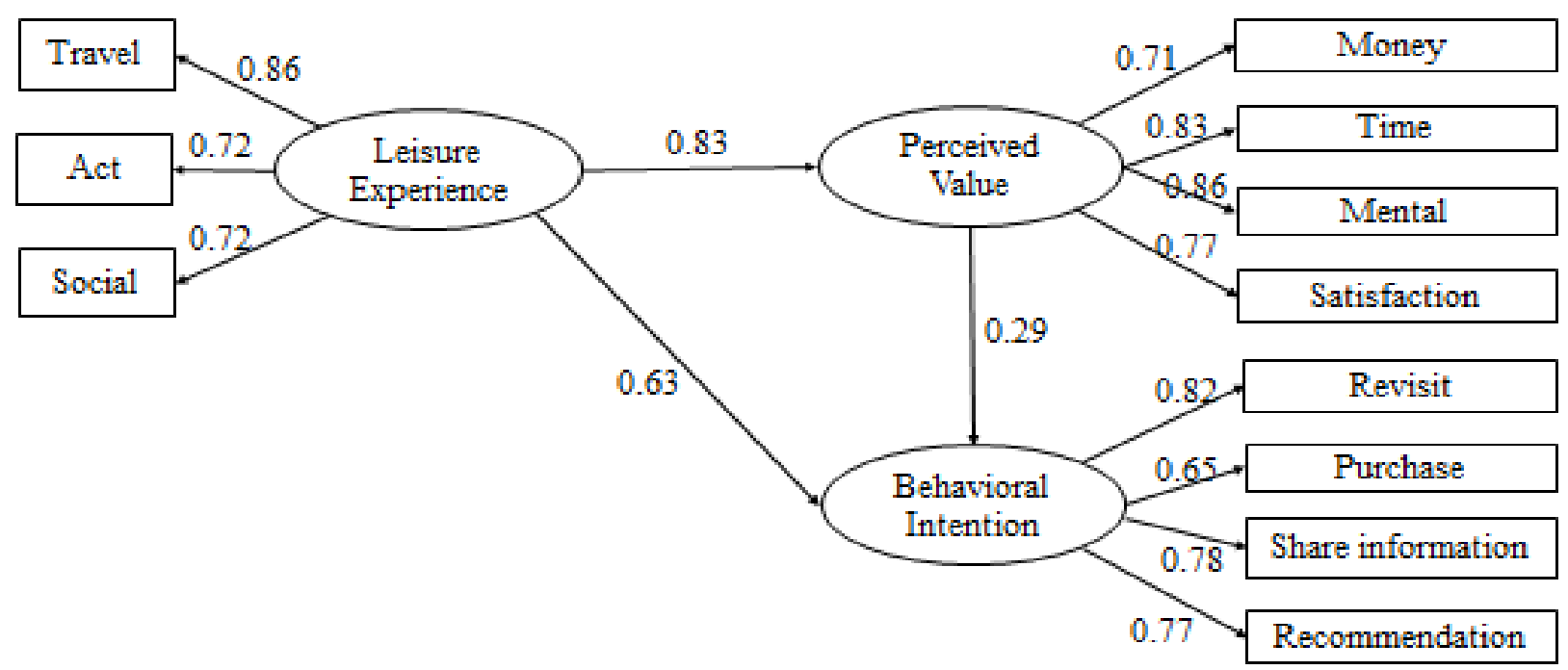

Figure 1. Structural Equation Model of Leisure Experience, Perceived Value and Behavioral Intention 


\section{Conclusions}

\subsection{Findings of the Study}

The study aimed to explore the relationship among leisure experience, perceived value and behavioral intention, after path analysis found that:

\subsubsection{Leisure Experience with Perceived Value}

Leisure experience to perceived value with path coefficient of 0.83 and the $t$ value $10.86, p<.05$, in which meant that the leisure experience would positively affect the perceived value in Xitou Monster Village. H1 established, the reason might be the tourists feel the uniqueness and atmosphere in monster village, resulting in wonderful experience, and thus enhance the sense of the value in the monster village. This is the same result with the finding of Chang [29] to explore the leisure experience and perceived value, the study showed that leisure experience would positively affect the perceived value of the tourists.

\subsubsection{Leisure Experience with Behavior Intentions}

Leisure experience to behavioral intentions with path coefficient of 0.63 and the $t$ value $5.18, p<.05$, in which meant that the leisure experience would positively affect the behavioral intention in Xitou Monster Village. H2 established, it was assumed that special atmosphere and experience activities building up the wonderful feelings of visitors, therefore, prompting tourists willing to share their experiences and recommendations to friends and relatives, and they are willing to visit and spend money to buy goods again. The result of this study was similar to Yeh [30], investigating the tourists and behavior intention, the research indicated that visitors' experiential quality will positively affect the behavioral intentions.

\subsubsection{Perceived Value with Behavioral Intentions}

Perceived value to behavioral intentions with path coefficients of $0.29, \mathrm{t}$ value of $2.46, \mathrm{p}<.05$, this represented that perceived value would directly impact on behavioral intention in Xitou Monster Village. H3 established, the result might be from various costs or expenses minus feelings after receiving, obtained more positive evaluation, the researchers believed that the visit or play were worthy, and then a positive influence to their behaviors. The results of this study was similar to the research of Hsu and Chung [25], the result of the study showed that visitors' feelings of the perceived value had a positive influence on their behavioral intentions.

\subsubsection{The Relationship among Leisure Experience,} Perceived Value and Behavioral Intentions

This structural equation model construct of leisure experience, perceived value and behavioral intentions, all $\mathrm{t}$ value showed in significant level (see Figure 1), H4 sustained, in which meant that leisure experience may influence behavioral intentions through perceived value, the reason it might be resulted from tourists experienced of various services, and then the tourists would first yield evaluation of perceived value, and then based on these evaluations in turn to generate subsequent behavioral tendencies and intentions.

\subsection{Managerial Implications}

According to statistical analysis procedures, this study construct leisure experience, perceived value and behavioral intention structural equation model, based on the findings and discussion, lists the following managerial implications:

This study successfully constructed the structural equation model of leisure experience, perceived value and behavioral intentions, all path coefficient showed in significant level; therefore, for managers of Xitou Monster Village in planning and running various marketing activities, not only consider tourists marketing activities experience feelings, but also taking into account the perception of the value of leisure experience, and then can really enhance behavioral intentions.

The study found that leisure experience will positively affect the perceived value, so if enhance the leisure experience positively, can improve the perceived value of the tourists. From Figure 1 can be found, the highest coefficient in leisure experience was travel experience variable, thus, while the organization should build up the leisure experiences, can strengthen the organizational resources priority into the travel experience to have a better output. Furthermore, analysis of Table 1 in the questions of travel experience, most of its content and experience on relating to facility specialty and atmosphere establishment, so in the strengthening of the travel experience, organizational resources can be concentrated in creating facility characteristics and atmosphere, for example, unique sensory stimulation, distinctive mascot display, developing related products and creating a casual atmosphere, those were worth the effort. It is worth noting that this experience should be part of emphasize to create the overall environment for the spindle, every single activity should be considered as a part of overall experience.

The study found that tourists perceived value will positively affect the behavioral intentions, so if increases the tourists' perceived value, and will enhance the performance of behavioral intentions. All four variables in perceived value showed that mental and time variables had highest in path coefficient (see Figure 1); therefore, the organization should place resources in those variables for improvement in transportation service and observation direction and routes. In transportation improvement could have cooperation with local public bus company to have shuttle bus service, and designed clear public transit route map and tour package; in visiting route could be arranged through visitors' demands in majority observation stands, such as shopping stands, praying route and other programs for selection, so that the tourists can pay less attention and energy saving to experience the essence of Xitou Monster Village. 


\subsection{Recommendations}

According to the result of the study and discussion, recommendations listed as follow:

The study had successfully construct the model of relationship among leisure experience, perceived value and behavioral intentions, other variables in further studies should be added to explore the effects of tourist behaviors, such as involvement, service quality, satisfaction to make the study much more complete.

The main purpose of the research based on tourists from Xitou Monster Village to study the relationship among experience, perceived value and behavioral intentions, suggestions for further studies should apply various ethnic groups to explore applicability of different types of tourist behaviors.

\section{REFERENCES}

[1] Kao, S. Y., Wang, D. Z. \& Chang, L. H. (2009). The effect of leisure experiences upon leisure benefits and leisure satisfaction: A study of policemen in Penghu. NPUST Humanities and Social Science Research, 3(4), 108-128.

[2] Tourism Bureau. (2011).http://www.taiwantourbus.com.tw/L ocation/Content/?id=298

[3] Liu, W. K. (2007). The magic power of style. Common Wealth Magazine, Taipei.

[4] Pine II, B. J. \& Gilmore, J. H. (1999). The experience economy: work is theatre and every business a stage. Harvard Business School Press, Boston.

[5] Bruner, J. (1986). Actual minds, possible worlds:(2nd).Cambridge, MA: Harvard University Press.

[6] Schmitt, B. H. (1999). Experiential marketing. Journal of Marketing Management, 15(1), 53-67.

[7] Shen, C. C., Tseng, T. H. \& Lin, Y. S. (2008). Tourist's leisure involvement, experience, and attachment - A case study of Nantou Shui-Li Snake Kiln Ceramic Park. Journal of Humanities and Social Science of NHCUE, 1, 113-132.

[8] Chung, C. C. (2008). The relationship between the consumer experience and the behavioral intention in professional baseball. Sports \& Exercise Research, 10(1), 35-45.

[9] Lai, C. H., Chung, C. C., \& Pan, W. H. (2005). A study of the relationship between experiential marketing and experiential values sport and health clubs: The case study of a fitness center. Sports \& Exercise Research, 7(3), 101-114.

[10] Chen, R. J., Kuo, C. W., \& Chung, C. C. (2012). A study of watching motivation, watching experience, perceptual value, and behavioral intention in baseball game spectators. Journal of Science and Technology, 21(3), 229-238.

[11] Zeithaml, V. A. (1988). Consumer perceptions of price, quality and value: A means-end model and synthesis of evidence. Journal of Marketing, 52(7), 2-22.
[12] Mathwick, C., Malhotra, N. K., \& Rigdon, E. (2001). Experiential value: Conceptualization, measurement and application in the catalog and internet shopping environment. Journal of Retailing, 77, 39-56.

[13] Chien, T. W. (2006). A Study of Consumers' Experiential Value in Blue Lagoon and Formosa Fun Coast Theme Parks. Journal of Sport and Recreation Research, 1(2), 84-100.

[14] Chang, L.H.(2013). The Relationships of Perceived Value, Word-of-Mouth, and Purchase Intention of Kinmen Kaoliang Liquor. Journal of Tourism and Travel Research, 8(2), $19-$ 35 .

[15] Petrick, J. F., (2004). The roles of quality, value, and satisfaction in predicting cruise passengers' behavioral intentions. Journal of Travel Research, 42(4), 397-407.

[16] Meng, S. M., Liang, G. S., \& Yang, S. H. (2011). The relationships of cruise image, perceived value, satisfaction, and post-purchase behavioral intention on Taiwanese tourists. African Journal of Business Management, 5(1), 19-29.

[17] Fan, T. Y., Liu, F. M., \& Wu, T. Y. (2014). The influence of corporate image, perceived value and website quality on the consumer loyalty to travel website. Journal of Business Administration, 103 (Dec.), 63-89.

[18] Engel, J. F., Blackwell, R. D., \& Miniard, P. W. (1995). Consumer behavior $\left(8^{\text {th }}\right.$ ed.). Fort Worth: Dryden Press.

[19] Parasuraman, A., Berry, L. L., \& Zeithaml, V. A. (1991). Understanding, measuring and improving service quality findings from a multiphase research program. In S. W. Brown, E. Gummesson, B. Edvardsson, \& B. Gustavsson (Eds.), Service Quality: Multidisciplinary and Multinational Perspectives (pp. 253-267). New York, NY: Lexington Books.

[20] Baker, D.A., \& Crompotn, J. L.(2000). Quality, satisfaction and behavioral intentions. Annals of Tourism Research, 27(3), 785-804.

[21] Kotler, P. (2003). Marketing management. NJ: Prentice-Hall.

[22] Chen, C. F. \& Chen, F. S. (2010). Experience quality, perceived value, satisfaction and behavioral intentions for heritage tourists. Tourism Management, 31(1)1, 29-35.

[23] Chung, C. C., Tsai, L. T., Tsai, W. C. \& Huang, M. L. (2010). A study on visitors' destination image, participation experience and behavioral intentions in cultural festivals - An example of taking part in Lantern Festival at Chao Tien Temple in Beigang. Leisure Industry Research, 8(4), 19-44.

[24] Prayag, G., Hosany, S., \& Odeh, K. (2013). The role of tourists' emotional experiences and satisfaction in understanding behavioral intentions. Journal of Destination Marketing \& Management, 2(2), 118-127.

[25] Hsu, H. C., \& Chung, C. C. (2011). The relationship between destination image, experience, perceived value, and behavioral intentions of hiking trail visitors. Journal of Taiwan Society for Sport Management, 11(3), 233-253.

[26] Yi, S., Day, J. \& Cai, L. A. (2014). Exploring tourist perceived value: An investigation of Asian cruise tourists' travel experience. Journal of Quality Assurance in Hospitality \& Tourism, 15(1), 63-77. 
[27] Yeh, P. Y., Hsu, Y. W., \& Chung, C. C. (2010). A study of leisure experience and behavior intentions of tourists. 2009 China Annual Symposium on Leisure and Social Progress, 2010/10/23-26, International Sociological Association, Beijing China, 52-53.

[28] Huang, F. M. (2004). The statistical methodology for social science. Wu Nan Books, Taipei.

[29] Chang, H. M. (2009). A study of tourist cognized on costal sport tourism attractions, travel experiences, perceived values, and behavioral intention. Journal of Leisure and Recreation Industry Management, 2(3), 31-55.

[30] Yeh, P. Y. (2010). A study of the relationship between attraction, leisure experience and behavioral intentions among the butterfly watching activities. Unpublished master thesis, National Yunlin University of Science and Technology, Yunlin, Taiwan. 